wound of the vulva. This knife was identified as O'Neil's; Haley had seen him cutting tobacco with it during the afternoon of their carouse. It was a knife such as a shoemaker uses for trimming soles; it had a blade about four inches long, which had become somewhat concave at its edge by long use and repeated grinding, but its rounded point was well sharpened. This blade was fixed firmly in a wooden handle. ' 1 his weapon, if such it was, was found secreted behind a looking-glass in the kitchen, on the morning of the woman's death. It was given by the finder to another woman, who placed it in her stove for safe keeping over night. A fire was made in the stove by a third person, who had no knowledge of the contents of the oven, and the consequent baking and charring destroyed all evidence of blood-stain, if any existed. The person who found the knife testified that it was clean and bright when she first saw it.

But it will be proper to ask if such a wound necessarily implied the use of a knife to produce it. May not the lesion have been a contused wound, the result of a kick, the blow being received in such a direction and situation as to cause a solution of continuity simulating an incision. It is well known that the appearances of a cut may be closely imitated by a smart blow from a blunt instrument upon soft parts overlying bone, and cases are not wanting in which a wound of the vulva produced by a kick or a fall has given rise to grave doubt whether or not a weapon has been used. ${ }^{1}$ While admitting the possibility of fatal hæmorrhage from a contused wound of the pudendum, and even granting that a kick with the shod foot might divide the tissues and leave something of the appearance of a cut upon them, it must nevertheless be insisted that the vertical direction of the lesion in the present case, its clean-cut, regular edges, its smooth inner surfaces, the absence of swelling and of ecchymosis in the adjacent parts, are quite strong points of proof that a cutting rather than a blunt instrument was used.

But however wisely or wildly we may speculate upon questions whose solution is difficult or impossible through a want of satisfactory data, the most important feature of the case remains well-founded, as an instructive medico-legal fact, and it is to this that $I$ give the concluding word. 'This is the material and significant reality that within the space of five hours (taking outside limits of time) a strong, plethoric, and healthy woman bled to death by a wound of the vulva an inch long and half an inch deep. Such an occurrence, if standing alone as one observed for the first time, would be regarded as extraordinary, perhaps as incredible; but it is fortunate in being in accord with similar observations recorded in surgical and medico-legal writings. It is really a typical example of an interesting class. Ogston $^{2}$ quotes the case of a woman who died in ten ninutes after receiving two wounds about the genitals, one on the left labium and the other at the entrance of the vagina at its upper part; the fact that she was pregnant, and that the vascularity of the parts was thus increased, may have had some influence upon the rapidity of the hæmorrhage. Taylor ${ }^{8}$ alludes to the case of a woman, eight months pregnant, who "fell from a chair, which also fell with her. There was hæmorrhage, and she died in a quarter of an hour.

1 Taylor's Principles and Practice of Medical Jurisprudence, i., p. 678 .

2 Lectures on Medical Jurisprudence, p. 486.

8 Principles and Practice of Medical Jurisprudence, i., p. 677.
The blood had flowed from a wound an inch and a half long, situated between the right labium and the urethra." In another case " a contused wound of the clitoris proved fatal. A woman, aged thirty-six, received a kick from her husband in the lower part of the abdomen while she was in a stooping posture. When seen, in about three quarters of an hour, she had lost from three to four pounds of blood; she was sinking, and expired a few minutes afterward. The wound was at the edge of the vulva, extending along the ramus of the pubes; it was about an inch long and three quarters of an inch deep. The left crus clitoridis was crushed throughout its length." These cases are of use in teaching the medical witness that, whether in the presence of a jury or elsewhere, he should be economical in the use of terms like "impossible," or " incredible," or "inconceivable."

\section{A CASE OF ACUTE HEMIPLEGIC CHOREA; WITH AUTOPSY AND REMARKS.}

BY RalPh M. Canfield, M. D., and James J. PUTNaM, M. D.

THE following case is, from several points of view, one of unusual interest: first, as being a typical example of a comparatively rare affection, unilateral chorea in the adult, traceable to a distinct organic lesion in the brain ; then, because it is remarkable that this lesion - involving, as it did, a portion of the crus cerebri - did not give rise to paralytic symptoms of more pronounced character; and, finally, because of the points in diagnosis and treatment to which it calls attention.

The patient was a man of fifty-nine years, of large frame, and of robust type. For the past fifteen years he had been quite intemperate, and this habit had grown upon him, until for the past eight months he had taken daily six or eight potions of best rye whiskey, with now and then a spree of two or three days' duration. Otherwise his life had been an average one, and his family history is one of peculiar longevity, with no cerebral or other marked diseases. His wife says that for a year past he has been more irritable than formerly.

For some weeks previous to the onset of serious symptoms his family had noticed choreic movements in his right arm and leg, and for the last week a slight dragging of the leg. In ascending stairs, however, he had used his feet equally well, so that there could not have been any paralysis in consequence.

On August 5th his wife came to ask medical advice, and gave the above history, adding that the movements had become more violent and constant, but that they ceased entirely during sleep. The previous night, however, sleep had been impossible. The patient was ordered twenty grains each of bromide of potassium and hydrate of chloral, which gave him a comfortable night. The next day he was examined carefully and the following condition noted, which remained without essential change until shortly before his death :-

The right arm and leg were found to be in violent and constant motion of a distinctly choreic type, but involving the muscles of the larger joints - hip, shoulder, ete. - even more than those of the smaller.

The face was apparently still, but the articulation was nevertheless somewhat thick. At times the right

4 Lancet, October 31, 1846, p. 478. 
side of the face seemed to move less well than the left, but the tongue was protruded straight. 'The movements increased in violence when any attempts were made to use the limbs, and although the patient declared himself unable to check them by voluntary effort, yet it was striking to observe how, if the arm were drawn quietly to the side and the patient strictly enjoined to lie still and close his eyes, the movements would cease for a moment and the patient sink into a half sleep.

No diminution of gross strength could be observed in the affected arm or leg. The knee and ankle reflexes, which were normal on the right side, were wholly absent on the left. The plantar, cremaster, and umbilical reflexes were absent on both sides. The sensibility to the prick of a pin seemed less over the affected side, though this may have been due in part to the engrossing influence of the movements. No finer tests were possible. 'The patient complained of no pain or sense of numbness, but said the skin felt sore or raw, as if flayed, over the right arm and leg.

His intellect was slightly clouded, but at times, when aroused, he seemed quite rational.

The surface temperature of the right arm and leg was markedly higher on the right side, but perhaps not more so than could be accounted for by the constant motion. Still, these parts had a turgid feel, and the skin over them, as well as that over the right side of the face, was slightly reddened. 'There was no change in the acuity, or field of vision, nor in the movement of the eyes. Pulse full and strong; somewhat tense. Respiration normal. Heart not enlarged; sounds normal.

In spite of the movements the patient was able to walk across the floor to the bath-room without help. Micturition voluntary.

The temperature at this period was normal, or slightly elevated $\left(99.5^{\circ} \mathrm{F}.\right)$; but in the last days of the patient's life it ran up to $102^{\circ} \mathrm{F}$., the pulse and respiration becoming at the same time rapid and feeble.

The bromides, chloral, morphia, and valerianate of zinc were given in full doses, at different periods, to check the movements, but as they failed to do so satisfactorily the fluid extract of conium was substituted. Sixty minims of this were given the first day, and the dose was gradually increased until, on the third day afterward, he took six drachms in twenty-four hours. Then for the first time the characteristic effects were seen, namely, paresis, first of the eyelids, soon afterward of the arm, and later of the leg. The conium was then discontinued for the time.

The next day he seemed quite comfortable and took a generous diet, in̉cluding milk punch, beef peptonoids, eggs, chicken, etc. The involuntary movements had almost ceased, and he slept quite naturally during the night and somewhat during the day.

On the following day the movements reappeared. The conium was again commenced and carried up to full doses with but very little, if any, effect, and six days later (August 19th) Fowler's solution was substituted. Twenty-four minims in the twenty-four hours were given ut first, and the dose was gradually increased until, on August 22d, he took forty-eight minims, which produced the characteristic symptoms of puffing of the lids, etc. The effect of this seemed to be beneficial, but it had been evident for some time that the patient had been failing in both mind and body, and was now nearing his end.
On August 23d the pulse became small and weak, the temperature began to go up, the respiration became frequent and hurried, and his exhaustion increased rapidly. The stimulants were increased, but the system failed to respond. He became semi-comatose, and died August 25th, having been unconscious for the previous twenty-four hours.

On the day before his death the respiration numbered fifty-two and the temperature was $102^{\circ} \mathrm{F}$. On the morning of his death the respiration had reached ninety-two.

The autopsy was performed forty-eight hours after death. As the weather was warm the abdominal organs had become somewhat discolored and decomposed, rendering it difficult to affirm the presence or absence of finer changes of structure in them. The brain, however, was well preserved, and we shall confine our report to that, as being manifestly the seat of the disease.

Calvaria rather dense, but of even thickness and without erosions; dura unusually adherent in spots.

Dura normal, sinuses nearly empty of blood.

Pia not at all, or but slightly, opaque; contains a moderate amount of fluid in its meshes. No marked atrophy of convolutions. Vessels contain but little blood. About one ounce of nearly clear fluid left in skull after removal of brain.

Vessels at base of brain excessively atheromatous, the larger ones not collapsing at all when cut across. The lumen of some of the vessels is materially encroached upon by this degenerated tissue, which is separable in large flakes. All exposed vessels examined for plugging, but none found.

Ventricles of brain essentially empty.

Cut surface of hemispheres pale; clings to section knife; no puncta cruenta ; gray matter every where illdefined.

Parallel frontal sections ${ }^{1}$ were next made through the brain from before backward at intervals of about half an inch or less. No lesions were seen until the cut passing through the lase of the anterior transverse convolution and the anterior extremity of the nucleus lenticularis was reached.

Scattered over the cut surface of the latter ganglion, in the left hemisphere, were several minute, brownish spots of softening, two or three millimetres in diameter, not involving the capsula interna. In the corresponding ganglion of the right hemisphere, one or two similar spots were seen, and another, somewhat larger, in the white substance just above the nucleus lenticularis, and just at, or outside, the limits of the capsula interua, strictly speaking.

One or two similar spots of softening were seen on several subsequent sections, but they were confined to the nucleus lenticularis except at one spot, in the left hemisphere, where a portion of the capsula interna ad. jacent to a spot in the upper edge of the nucleus lenticularis seemed a little softened. Some of the spots were ratber linear than round, and evidently marked the course of vessels, although no distinctly thrombosed vessel were seen.

Up to this point both hemispheres had been nearly equally affected (the left, to be sure, the most), but the next and largest lesion involved the left side alone. This was first seen on the cut dividing the crura cerebri just after their emergence from the brain, as a dark brown spot about two millimetres in diameter, at the 1 After the manner of Pitres. 
junction of the middle and outer third of the pes cruris, a little below the substantia nigra. Careful examination subsequently showed that this spot was the lower edge of a mass of somewhat softened and partially necrosed tissue, of the size of a large pea, though of more oval shape, and with its long diameter passing obliquely inward and upward through the inner half of the crus. The substantia nigra was involved, and the neighboring portions of the tegmentum cruris, but the lesion did not penetrate the thalamus opticus, which appeared healthy on all sections. The only ganglionic matter involved besides the substantia nigra was (probably) the so-called ganglion of Luys. In other words, this collection of diseased tissue lay in the inner half (mainly in the inner third) of the crus cerebri opposite the posterior portion of the thalamus. It involved the substantia nigra, together with the pes cruris beneath, to the depth of five or six millimetres, and the tegmentum above almost to the centrum rubrum. It was bounded behind by a (frontal) plane drawn through the posterior edge of the corpus candicans, and in front by another plane nearly one centimetre in advance of this.

The diagrams given by Meynert at page 694 of Stricker's Handbook of Histology (American edition), and by Wernicke at pages 64 and 66 of his Lehrbuch der Gehirnkrankheiten, indicate very well the level of the lesion.

Cerebellum, pons, and medulla oblongata were normal, except that, like that of the rest of the brain, their tissue was very anæmic.

Microscopic examination of the softened tissue in the crus, as well as of the minute spots in the nuclei lenticularis, showed them to consist of disintegrated brain tissue, masses of granular bodies and granules of free fat, and occasional crystals of hæmatoidine. 'The walls of the smaller vessels contained masses of pigment, and their sheath was often crowded with granular bodies. The cells of the substantia nigra in the affected part were also seen to be in every stage of degeneration. Some of them were still recognizable from their pigment, while others had evidently lost their pigment, though still of characteristic size and shape.

The mode of onset and the progressive course of the disease in this case, - the clouding of the mental functions, the disappearance of the reflexes, the slight unilateral impairment of sensation and motion, - marked it, even before death, as being probably of organic origin, and to be ranked with the so-called pre- and post-hemiplegic disorders of movement. Nevertheless, before inquiriug into the physiological pathology of the chorea in its relation to the lesions actually discovered, it is important to bear in mind that equally violent and exactly similar movements are capable of coming on, and lasting for long periods, without the influence of any gross lesion whatever. ${ }^{1}$

A knowledge of this fact ought surely to make us careful what rôle we assign to the hæmorrhages and softenings that have been observed in cases like that before us, though it does not in the least impair the value of the many observations, which show, on the whole, a remarkable constancy in the seat of the majority of the lesions with which these disorders of movement, so far as they have been of organic origin, have been found to be associated.

It is unnecessary to review the history of this subect at any great length.

These disorders of movement were first called atten-

1 Thus see Kirchhoff, Arch. f. Psychiatrie, etc., xiii., p. 582. tion to by Mitchell, in 1874, and by Charcot at about the same period, under the name of post-hemiplegic chorea, and since then have especially engaged the attention of many observers.

The investigations of Gowers ${ }^{2}$ have made it clear that there is a whole family of symptoms of this class, embracing the post- (and pre-) hemiplegic chorea and the athetosis of Hammond, as well as a variety of intermediate forms, characterized by slow or quick, regular or irregular movements, some of them occurring only in connection with voluntary motions on the patient's part, others spontaneous or (as in the present case) only exaggerated during voluntary efforts.

Almost invariably these disordered movements are associated with incomplete paralysis either in the progressive or the regressive stage, but occasionally they occur without paralysis, and in one case a totally paralyzed limb has been reported to be the seat of the spasmodic movements. (Bernhardt. ${ }^{3}$ )

The different members of this family of symptoms are certainly closely related, since it sometimes happens that in the history of a single case several of these different forms of movement are successively or simultaneously present.

We must wait until more is known of the anatomy and physiology of the central nervous system, and until a larger number of autopsies have been made, before we can satisfactorily discuss the physiological pathology of these interesting phenomena.

Judged from the standpoint of gross anatomy, the bulk of the evidence points to the thalamus opticus and its immediate neighborhood, especially the region supplied by the posterior external thalamic artery, as the favorite seat of the lesion, ${ }^{4}$ and here it was found in the case before us, as well as in the similar one recently reported by Greiff. (Vide below.)

Significant as this fact is, however, it cannot be taken as proof that the symptoms are always due to a disordered action of that ganglion, for in other cases the apparently effective lesion has been found in the nucleus lenticularis, the capsula interna, the pons and medulla, the cortex cerebri, and, finally, it has been shown that similar symptoms may occur without any gross lesion whatever (see above), as in the chorea of children.

Although we cannot assert the cause of these symptoms, we can say that the explanation offered by a number of observers (Kahler and Pick, Démange, Greiff, 5 and others), that they are due to a direct irritation of the great motor tracts of fibres running from the brain to the spinal cord, is anatomically and physiologically improbable, and that it has really only its apparent simplicity to recommend it. Were this explanation correct, then lesions of these tracts at any part of their course should have this effect, whereas, in fact, it only follows lesions at or above the level of the medulla oblongata.

This is a significant fact when we remember that these are the lowest stations which contain coördinating arrangements of any complexity. Furthermore, it is

2 On Athetosis, etc., Med.-Chir. Trans., vol. lix., 1876; and Brain, 1878.

3 Berl. kl. Wochenschr., 1875, No. 35.

4 See the analysis of cases by Kahler and Pick; Beiträge zur Pathologie, etc., des Centralnervensystems, 1879; also Grasset, Maladies du Système Nerveux, p. 219.

5 Arch. für Psychiatrie, etc, Bd. xiv., p. 598. This observer reports with great thoroughness a case closely resembling our own both clinically and pathologically. 
noteworthy that no experimental excitations below the level of these organs are capable of causing generalized convulsions in animals. (Nothnagel.)

In other words, it would seem that the efficient factor is the irritation, not of the motor tracts of fibres, but of the ganglia lying near them.

It is true that many of the lesions found in these choreiform cases are in such a position that they might irritate the motor tracts. This is true also of our case. But so also there are other disturbances which these lesious might, and indeed must effect, and chief among them is the damaging of the associating tracts between the various cerebral centres, with which the direct motor tracts in the cerebral portion of their course are everywhere interlaced. This is, physiologically, almost equivalent to an injury of the centres themselves.

In our opinion, the most natural way of regarding these choreic movements is to suppose them produced in disease by similar means to those which would produce them in health.

There are various coördinating ganglia in the brain which, in health, probably act sometimes together, sometimes separately, in the production of coördinated movements. In disease these same ganglia are also sometimes set in action, but by some other than the normal mode of excitation, and in such a manner that the results of their activity suggest the motion of a machiue, of which the parts are out of gear or the balance-wheel destroyed. Why lesions in or near the thalamus opticus should be especially prone to produce this result cannot be explained.

In whatever way the motor-coördinating apparatus is called into this uncontrolled activity, the movements which come to the front are probably those expressing the average mode of activity of the ganglionic masses concerned, that is, they are movements of most habitual recurrence; and it is therefore not remarkable, that cases with different lesions, and with lesions in different localities, should bear a certain likeness to each other. Neither can we agree with Nothnagel in regarding it as improbable that similar lesions should give rise now to slow and regular, now to quick and irregular movements, unless, indeed, we deny that the individual himself makes use of one and the same nervous centres for movements of these different grades, a position which could not be maintained.

The case before us could not, to be sure, be used as an argument against the view of Kahler and Pick and Démange, since the lesion bordered closely on the motor (volitional) segment of the crus cerebri (the middle third), and even encroached on it to some extent. The bulk of the lesion, however, lay partly in the inner third of the pes cruris, partly in the fibres of the tegmentum, and it is this latter part of the lesion which, reasoning from the other cases reported, we suspect to have been the really efficient factor. It is not to be forgotten that there were several very small patches of softening in the nucleus lenticularis. Their influence in the result is problematical ; but from the fact that they were present to a nearly equal degree on both sides, it is not probable that they caused the purely unilateral choreic symptoms. Possibly the injury done to the substantia nigra, which receives fibres from the nucleus lenticularis, and discharges others into the pes cruris (Wernicke), may have played its part also in the result.

At all events this case is certainly to be ranged with the now considerable number of those in which the region supplied by the posterior thalamic artery has been found diseased, a fact for which at present no explanation can be given.

\section{THE CASES OF THE SURVIVORS OF THE LADY FRANKLIN BAY EXPEDITION.}

BY EDWARD h. GREen, Past assistant SURgeon, U. 8. N.

As a preliminary to a medical history of the cases of the survivors of the Lady Franklin Bay Expedition, it is well to give a brief résumé of their mode of life at Camp Clay, their quarters, rations, etc., so as to better appreciate the condition in which they were found.

On September 29, 1883, Lieutenant Greely landed with his party at Baird Inlet after thirty days' exposure drifting on an ice-floe. The record left at that time stated the party was all well. Having sent an advance detachment ahead, it was found and reported that a cache of provisions existed at Cape Sabine (fifteen miles farther to the northward than he was at this time); it was deemed expedient to move the whole command up to that neighborhood, rather than send for the provisions and winter at Baird Inlet. Finally, on October 25th, they moved around to a point between Cape Sabine and Cocked Hat Island (latitude $78^{\circ} 45^{\prime}$ N., longitude $74^{\circ} 15^{\prime \prime} \mathrm{W}$.). The site of their winter quarters was sheltered between high ridges of mountains, which screened them in a measure from the northerly and southerly winds. A glacier was situated at the foot of the mountain on either side of them about a mile distant. They constructed a house of loose rock and moss, the walls being three feet in thickness; the roofing consisted of old canvas stretched over a boat; the dimensions of the house were twenty-five feet long, seventeen feet wide, and four feet high, making the cubic air space 1,700 feet. In this the twenty-five members of the party lived all winter, having a cubic air allowance of about seventy feet for each man. The whole party could barely squeeze in and lie at length, two or three being obliged to occupy the same sleeping bag; the effect of this diminished air space will be seen later on. Their hut was but one hundred yards removed from the ice-foot of the Sound, and two bundred yards to the south of them was an artificial lake, from which they drew their water supply by melting ice. As the sea water strained into this lake, they were driuking brackish water all the while.

On November 1st Lieutenant Greely took a careful account of his stock of provisions, and found there was but a whole ration for each man (estimated as an army ration, about forty-six ounces solid food per diem) for forty days. Dr. Pavy and he advised together, and it was with some reluctance that they determined to divide up the rations so as to make them last until March 1st, putting aside from time to time, so that at the end they would still have ten days' supplies left with which to attempt the trip to Littleton Island if the straits were frozen over. Dr. Pavy did not think the party could exist on the ration during the winter, but the common voice was to make it go as far as it would, so each wan was given the following daily allowance:- 